\title{
North Korea's Cultural Diplomacy in the Early Kim Jong-un Era
}

\section{Adam Cathcart and Steven Denney}

\section{Structured Abstract}

Article type: research paper

Purpose-This article describes and analyzes the DPRK's cultural diplomacy during the early months of Kim Jong-un's reign.

Methodology - We analyze the recent practice of North Korea's cultural diplomacy, using two case studies: the KCNA-Associated Press photo exhibition in New York, and the tour of the Unhasu Orchestra to Paris.

Findings - Both initiatives coincided with the first months of Kim Jong-un's reign, and can provide an alternate perspective on both North Korean foreign policy and the wider debate about how to best engage the DPRK.

Originality/value - The article thus adds to the literature on North Korean foreign relations as well as cultural diplomacy more generally.

Keywords: Associated Press, Kim Jong-un, Korean Central News Agency, North Korean cultural diplomacy, North Korean foreign relations, public diplomacy, soft power, Unhasu Orchestra

\footnotetext{
Adam Cathcart, School of History, University of Leeds, West Yorkshire, LS2 9JT, United Kingdom; Office: +(44) 0113-34-35585; a.cathcart@leeds.ac.uk Steven Denney, University of Toronto, 100 St. George Street, Sidney Smith Hall, Room 3018, Toronto, Ontario, M5S 3G3; steven.denney@mail.utoronto. ca
}

North Korean Review / DOI: 10.3172/NKR.9.2.29 / Volume 9, Number 2 / Fall 2013 / pp. 29-42 / ISSN 1551-2789 (Print) / ISSN 1941-2886 (Online) / (c) 2013 McFarland \& Company, Inc. 


\section{Introduction}

Since the accession to power of Kim Jong-un, the North Korean state has lost no time in establishing the appearance of an accelerated internationalization. ${ }^{1}$ One important element in this process has been what is, by North Korea's own closed standards, a rather vigorous program of cultural diplomacy. The performing arts have been at the forefront of these exchanges and activities. In 2012, a North Korean symphony orchestra traveled to France, and North Korea's huge "Sea of Blood" opera company toured all over China. Meanwhile, at home, a new brand of North Korean regime-pop, christened the Moranbong Band, was even used to tantalize Western commentators with visions of a North Korean "opening up." Photography exhibitions went forward with the U.S., musical exchanges continued with Norway and Germany, and joint film projects with China also emerged as important elements in cultural diplomacy. These elements are part of a developing North Korean "soft power" strategy which complements and assists the country's diplomatic and strategic goals.

When discussing North Korean soft power, however, context matters more than ever before. Spring 2012, the time frame under consideration in this article, was a period of extreme activity by the DPRK on the world stage, culminating in a muchanticipated and -protested missile test on April 13, 2012. Given that the DPRK's cultural diplomacy in that period coincided also with domestic propaganda that was intensely xenophobic even by North Korean standards, it is possible and probably likely that the reasons behind the move to engage in cultural diplomacy in early 2012 were purely tactical. These soft-power efforts thus bear upon North Korean politics of aid as well as nuclear weapons. This is not to say that the efforts were fruitless or not engaged in willingly with the American and French partners who we discuss in this article. In both cases, the DPRK enlisted the collaboration of legitimate partners (the Associated Press and France Radio Orchestra) and an actual audience for their art, music, and a political message thereby. The support of legitimate partner institutions aids in illustrating that cultural diplomacy has served an important and limited success for the Kim Jong-un regime, if only meant to show domestically as a sign of the DPRK's growing internationalism. Finally, looking into the interactions more deeply allows for greater insight into the questions of whether Kim Jong-un's rule represents, portends, or only feigns a bona fide internationalization of the DPRK.

\section{IR Theory, Cultural Diplomacy and North Korea's History}

Power, a somewhat nebulous concept defined succinctly as the ability to affect others, lies at the center of international relations (IR) theory. This concept has traditionally been explained in a bifurcated way, describing how one state affects another state's behavior through some combination of coercion and inducement, an understanding of power best represented by the "carrot and stick" idiom and recorded in 
the IR dictionary as "hard power." Though realists, neoliberalists, and constructivists are not ineluctably bound to use conventional IR theory analysis, even a cursory reading of the available literature - old and new - reveals the dominance of hard power analysis. Since the end of the Cold War era, however, the introduction of "soft power" opened up an alternative conceptualization of power. ${ }^{2}$ Soft power emphasizes a state's use of "attraction" to get others to want the same thing they want without resorting to the use of coercion or inducement. ${ }^{3}$ In other words, soft power augments the state's ability to peacefully project and aggrandize its overall power in the international system. Most importantly, the way a state "attracts" other states is not by threat of military force or financial sanctions, but through the use of cultural resources: cinema, sports, art, literature, rock bands, radio broadcasts, symphony orchestras, and other forms of culture. The use of such resources as a form of soft power is known as cultural diplomacy. We are unaware of specific literature on soft power in materials studied within the halls and foreign outposts of the North Korean Foreign Ministry, but it would be virtually impossible for them to be unaware of the concept. After all, Chinese foreign affairs journals - which tend to be relatively the easiest to access for North Koreans - have been promoting the concept widely in the past three years, and in 2012 the concept even became a major leg in Hu Jintao's final report to the Party Congress. Notably, Chinese efforts to harness soft power could be particularly attractive to North Korean counterparts because the Chinese understanding of the concept emphasizes that an understanding of soft power is necessary so that one can defend one's own country from the soft power depredations and plots of the capitalist states, particularly the U.S.

\section{North Korean Cultural Diplomacy: A Historical Perspective}

Despite its popular portrayal as a "rogue state" whose modus operandi revolves around the reckless use of brinkmanship - nuclear and otherwise - as a means to dupe the outsider world into conceding aid to prop up the ruling elite, North Korea, too, has a historical foundation for the use of soft power through its use of cultural diplomacy.

In the "liberation" period from 1945 to 1948, North Koreans were engaged in forms of cultural diplomacy even before their state was established. ${ }^{4}$ Due to strong Soviet support and an ambivalent American occupation government to the south, Pyongyang was able to lure artists and other "leftist" intellectuals and artists residing in the south across the 38th parallel and into the Soviet-occupied zone. Following the signing of an agreement on cultural exchange in 1949, USSR-DPRK cultural interaction increased significantly. In addition to the North's adoption of Russian as its second official language, Charles Armstrong finds, "North Korean dance troupes, literature, and arts were brought to the Soviet Union." Through channels such as the Korean-Soviet friendship society, many North Korean writers found a publication outlet through which to propagate their political ideas. ${ }^{5}$ In the meantime, the North Koreans had an attentive audience among the Chinese communists' material in northeast China (and ultimately Beijing). Many of those in this audience legitimately saw 
North Korean culture as worthy of emulation. North Korea has hardly been in a state of perpetual tutelage, particularly when it comes to its relationship with Chinese culture.

North Korea's strategy for cultural diplomacy grew in earnest during the Korean War, combining fulsome Stalinist paeans along with the more pressing need for donations for the home front. Archives in East Germany and China are full of examples of North Korean musical troupes on tour during the Korean War, wishing to extend their stays away from the bombed-out cities of the DPRK, eating well, and collecting as much material as possible to convey back home. In 1952, several large delegations of North Korean performers set out for a European tour with the goal of raising funds for the Korean War effort. German audiences were appreciative, lavishing funds - and even books and electronic drill presses - on the DPRK state chorus, children's choirs, select wounded veterans and Korean People's Army (KPA) General Kim Il. The East German bureaucrats who were organizing the multiple performances noted that choirs made up of North Korean orphans were particularly effective in eliciting donations from audiences. ${ }^{6}$

While these interactions unmistakably took place under the mantle of Stalinism, they should not be dismissed out of hand as a purely coercive Stalinist construct. Even in the 1950s, the North Koreans were gaining understanding and experience in conducting international tours and projecting a national identity into the international sphere. This almost-comprehensive interaction, however, was cut short by the purges and cultural retrenchment of the period 1956-1958. Much in the same manner that Zhdanov's decrees of 1948 had warned Soviet cultural producers that their internationalism and contacts cultivated with well-meaning foreigners during World War II had actually only brought danger to the body politic, North Korean intellectuals and cultural workers were encouraged after 1956 to see the Soviet thaw as more than a bit dangerous. ${ }^{7}$ While interactions were curtailed with the purges of 1956, North Korea's limited internationalization and external cultural diplomacy during the prior decade should not be forgotten.

In the late 1960s, the intensification of the Kim personality cult and tensions on the peninsula meant that cultural diplomacy largely took the form of setting up Juche study groups in developing and recently decolonized states, and inviting foreign radicals to Pyongyang. After regional tensions peaked around 1968, the DPRK sent dancers to Paris during the détente of the early 1970s and, moving forward, a series of the April 15 Arts Festivals and then the 1989 Youth Games. However, interaction with the outside world was still very much governed by totalitarian sensibilities that refused to allow in rock music (the medium very much implicated in the East German collapse) or democratic influences from around the region, not least of which was the student movement in Beijing in spring 1989, an event which indicated clearly the volatility of cultural connections.

In more recent times, the visit of the New York Philharmonic to North Korea from February 25 through February 27, 2008, was considered by some to be a groundbreaking, if far from pivotal, episode in the rocky history of U.S.-DPRK relations and North Korea's efforts to engage the Western world through cultural diplomacy 
more broadly. The visit was largely hailed in the world press as a significant event. As one overoptimistic Chinese analyst put it, North Korea's willingness to accept the U.S. guests was considered "a turning point that would improve the two countries' bilateral relationship," possibly leading towards an official visit from former U.S. president George H.W. Bush. ${ }^{8}$ North Korea received positive coverage in the world media, not least of which included the New York Times, and then proceeded in the following year to ratchet down on relations with Washington and rattle the new Obama administration (as well as the DPRK's regional allies) with successive missile and nuclear tests. ${ }^{9}$

While the political and diplomatic backdrop upon which the visit took place soon collapsed along with the Six-Party Talks, North Korea's efforts to engage the world through cultural means has not. Kim Jong-il's heavy emphasis on military-first politics during most of his reign largely proscribed any serious efforts at further international engagement through cultural diplomacy with nonsocialist states, but the first eight months of Kim Jong-un's rule suggested that he and the ruling elite were taking a different approach towards the handling of North Korea's external relations simultaneous to bolstering its military deterrent. North Korean media, after all, was careful to depict Kim Jong-un's active management of the national artistic and musical patrimony in the same period, as well as the military. Through examining North Korean dealings with a key American news agency, the Associated Press, along with a French orchestra in Paris, it becomes clear that cultural relations played, not just a prominent role in the early months of Kim Jong-un's rule, but an important role that complemented the DPRK's more traditional efforts to project an intimidating militant façade.

\section{KCNA-AP Joint Photo Exhibition}

If there is one country on earth that takes the politics of imagery seriously, it is the Democratic People's Republic of Korea. Desecration of a flag or a portrait of one of the Kims is considered nearly unforgivable, and the national media will lash out with vituperation at outside forces that do not handle "the dignity of the DPRK" earnestly in the visual realm. A North Korean offer to engage in a joint exhibition of images, then, is not to be entered into lightly. The Korean Central News Agency (KCNA) and the Associated Press (AP) held a joint photo exhibition in a small gallery in New York City for one month in the spring: March 15, 2012-April 13, 2012. Officially entitled "Window on North Korea," the exhibition comprised a total of 79 photographs, a compilation of KCNA stock photos, the work of AP photographersincluding AP Chief Asia Photographer David Guttenfelder - and new KCNA photos of life in North Korea. ${ }^{10}$ The event was held as part of the agreement to open an AP bureau in Pyongyang, making it the first Western news agency to establish a bureau in the North Korean capital city and representing the culmination of the AP's effort to upgrade its staffing presence from remote to full-time in the capital city. ${ }^{11}$ The negotiations which led to the agreement appear to have followed a typical path 
of protracted Western overtures, which, once the North Koreans found it satisfactorily useful, moved forward, resulting in the signing of two Memoranda of Understanding (MOU) with KCNA in the first half of 2011, the second of which included the agreement to host a joint photo exhibition. ${ }^{12}$

The North Korean agreement to allow the AP a bureau in the country's capital can be read in several ways: first, as the DPRK government engaged the U.S. for the purpose of obtaining food aid, the agreement with the AP could be read as a type of preliminary concession by North Korea and the establishment of more of a "direct channel" to Washington. The fact that the DPRK did not engage in such negotiations with comparable news agencies in countries where it already had diplomatic relations-for example, Britain's BBC or Germany's Deutsche Welle - indicates that the U.S. connection gained through the relationship with AP was significant. Secondly, in exchange for opening a Pyongyang bureau, the AP, as part of its memorandum, agreed to host the joint photo exhibition in New York City. Such an exhibition could be interpreted as a tangible prize for a North Korean foreign affairs and propaganda bureaucracy desirous of a boost to the celebrations marking the 100th anniversary of the country's founder. While North Korean propaganda frequently describes worshipful treatment of Kim Il-song and his nation in foreign lands such as Nigeria, Nepal, and Peru, an exhibition in the heart of Manhattan with one of America's top news organizations could be conceived of on a higher sphere of significance. Finally, by concluding the deal with the Associated Press, the North Korean government, through KCNA, was able to borrow the prestige of the AP in its strategy to legitimize its efforts abroad and accelerate at least the appearance of the internationalization of the DPRK. ${ }^{13}$

Despite Kim Jong-il's death in December 2011 and the announcement of a pending missile launch that would scuttle the February 29, 2012, "Leap Day" agreement with the United States, the joint photo exhibition went on.

The event's opening ceremony on March 15 included representatives from both the KCNA and the AP, in addition to the gallery's cofounder, Donald Rubin, U.S. citizens, and members of the DPRK mission to the UN in New York. First ViceDirector General Kim Chang-gwang led the KCNA delegation and Senior Vice President Kathleen Carroll and Vice President John Daniszewski represented the AP. State Department officials were presumably instructed to steer clear of the event, but all parties involved clearly considered the exhibition a positive step forward in North Korea's relationship with the United States. ${ }^{14}$

The official AP press release emphasized the "uniqueness" of the images offered as a way of getting a "rare glimpse into a nation long shrouded from view," the entire exhibition "designed to show what life is like in the Democratic People's Republic of Korea (North Korea)."15 In her opening remarks at the exhibition, AP's Senior Vice President Carroll emphasized that the photographs and works of art on display "show [the] U.S. that different people can find common ground." AP Chief Asia Photographer David Guttenfelder cited photographs as having the "power to break down barriers" and emphasized how ordinary people could connect with North Korean citizens by relating to their lives as they are shown in the photos. ${ }^{16} \mathrm{KCNA}$ 's film of Don- 
ald Rubin's congratulatory speech may prove telling, particularly his "hope that the exhibition would be the first step towards cultural and political reconciliation." Also noteworthy is Kim Chang-gwang's expectation that the exhibition, as a North Korean cultural export, would promote "mutual understanding between the peoples of the DPRK and the U.S. and improving the bilateral relations."17

North Korean coverage of the event was somewhat less sanguine toward U.S.DPRK rapprochement. To emphasize ostensible "genuineness" of the event, the KCNA incorrectly, but certainly intentionally, identified the "theme" of the exhibition as the "True Picture of Korea," rather than using the official title of the exhibition. The KCNA claimed the photos depict the "undying revolutionary exploits" of the Kim paternal dynasty towards the "building of a thriving nation, people's happiness, independent and peaceful reunification of Korea and global independence."18 Despite the AP's stated intentions, as revealed in the title of the event, the notion that the photos on display offered an accurate reflection of daily life inside North Korea is a sellable line only to those woefully ignorant of actual conditions inside North Korea. With the exception of a few slightly revealing photographs by Mr. Guttenfelder - one of a lone policewoman directing ghostly traffic and the other a highrise building shot of urban landscape in Pyongyang that seems more like a sketch of a complex prison system - all the photographs on display provided views of the DPRK entirely in accord with the regime's own highly reified view of itself. ${ }^{19}$ The contrast between the carefully staged show in New York and what was going on domestically at precisely the same time - a huge wave of anti-Lee Myung Bak domestic propaganda that included burning of Lee Myung Bak in effigy and explicit threats to attack the Blue House - could not have been more clear. The missile test announcement only compounded the contradictions. The timing of the event with the AP seemed to assure that North Korea was on the Western stage at precisely the right time.

Despite the contradictions, merely writing off the event as a North Korean propaganda coup and a shameless agreement by the AP to a quid pro quo with an even more shameless DPRK bureaucracy shuts the door to entertaining a broader, more significant point: the use of the AP, the New York episode in particular, was and remains an integral part of North Korea's efforts to internationalize and engage the world - particularly the United States - through the use of cultural diplomacy. Should the exhibition, then, be read as an effort by the KCNA to promote relations with the U.S. government or the American people directly, via the AP? Though the AP, like its British counterpart Reuters, or Korean equivalent Yonhap, has a distinctive international presence, it is associated with the country it is incorporated in. The fact that, by North Korean standards, print media is merely an extension - or mouthpiece - of the central government most likely affects the way it understands and approaches its relationship with the AP. That the two AP employees posted to the Pyongyang office are Americans adds to the distinctive American qualities of the AP and certainly influences the way the DPRK government approaches its interactions with the New York City-based news agency.

Whether the North Koreans actually believe the AP is feeding the U.S. government information, or that American reporters in Pyongyang are receiving instruc- 
tions from Washington, though highly unlikely, is open to speculation and must, at least, be considered when trying to understanding DPRK motivations. Unlikely scenarios aside, the notion that the North Korean government is attempting to use alternative channels of communication to foster better relations is worthy of contemplation and pulls from the past the case of Edgar Snow's interview with Chinese Premier Mao Zedong, during which Mao revealed to Snow in somewhat cryptic language, not at all unusual for Mao, that he sought rapprochement with the U.S.

Will this endeavor bear fruit and prove to be a genuine "trust-building exercise" leading towards a U.S.-DPRK détente, as AP Vice President and Director of Photography Santiago Lyon believes? North Korea has been granted the upper hand in the realm of photo-diplomacy. How DPRK will use its newfound leverage is not yet manifest.

\section{The Unhasu Orchestra in Paris}

Unfolding roughly concurrent to the exhibition in New York, a North Korean orchestra traveled to France in March 2012 for a joint concert with a governmentfunded orchestra in Paris. As with the AP exhibition, which was presumably about people-to-people ties, a great deal of the messaging back to North Korea about the trip was about the greatness of the Kim family. The vehicle for this visit, the Unhasu Orchestra, had already been clearly identified in domestic propaganda with the benevolence and specific patronage of the ruling Kim family. Kim Jong-il's personal association with the orchestra was particularly intense: there were few greater signs of political approbation in the DPRK than to be invited to appear with the Dear Leader at one of the orchestra's regular performances, and, after Kim Jong-il's death, by the filial audiophile Kim Jong-un. Only with the rise of the Moranbong Band in July 2012 was Unhasu Orchestra's political primacy as a North Korean musical ensemble challenged and surpassed. While the KCNA exhibition in New York sang the praises of the suryang system, the Unhasu concert was a more striking (if subtle) manifestation of that system.

Like the AP exhibition, the Unhasu trip was perfectly timed to coincide with North Korea's drive to appear globally influential leading up to the 100th anniversary of Kim Il-song's birth, and for its missile tests to appear globally significant. It also played a specific role in diverting French and European narratives of human rights abuses in the DPRK as well as supporting North Korea's diplomatic drive to receive food aid from the European Union (EU) in the aftermath of the "Leap Day" deal falling apart with the United States. Apart from the missile test/satellite launch itself, the orchestra's visit to Paris was one of the primary active, action-oriented elements in North Korea's external propaganda in March 2012. The dispatching of the Unhasu Orchestra to Paris followed three distinct narratives in North Korean foreign relations.

First, it was intended as a preliminary move in an ongoing cultural diplomacy chess match with South Korea, holding out the prospect of a similar activity in Seoul. 
Not coincidentally, the conductor of the French National Radio Symphony is Chung Kyong-hwa, a famous South Korean who has been outspoken about the need for a joint Korean orchestra concert in Seoul or elsewhere. Using his orchestra as formal agency and partner which invited the Unhasu to Paris, Chung was moving ahead with his dream in a third country rather than on the Korean Peninsula. Chung had traveled to Pyongyang the year prior with the conductor of the Seoul Metropolitan Orchestra to set up preliminary cooperation for a joint Korean concert. When political conditions dictated that no inter-Korean orchestra arrangement could occur, he pushed forward via the French route and found the government in Paris to be rather receptive to the idea.

Second, the Unhasu Orchestra's concert in Paris was intended to serve as a reasonable counternarrative to the rising chorus of discontent in world media over the DPRK's announcement of the missile test for a satellite launch slated for April 13. The concert was timed precisely to coincide with the aftermath of that announcement, resulting in maximum publicity. Although there were a few pieces of North Korean propaganda that afterwards compared the orchestra to an atomic bomb (and the missile itself was named Unha-3), for the most part this was the line that was followed.

The third primary aim of the concert was to reward the French state and further warm it up for the ongoing drive toward normalization with Pyongyang. Kim Jong-un was in need of some immediate diplomatic triumphs, and this could be seen as one. The participation of French officials (François Mitterand and Jack Lang) in the Unhasu visit accordingly emphasized the state-to-state aspects of the visit in North Korean domestic news. Concurrent to this push with France, a side benefit could be garnered by having the DPRK appear to be more reasonable from the EU perspective at a sensitive time for food aid and as a riposte to accusations of North Korean human rights violations, which have a tendency to spring across the continent. The improvement of the DPRK image in Europe is far from the nation's top foreign policy priority, but it is one specific area where Kim Jong-un could garner further relatively easy prestige by improving relations and thus banking on his education.

It should be no surprise, then, that Kim Jong-un and other high-level leaders were far more visible in the case of the Unhasu Orchestra than they were in the case of the AP-KCNA deal. Kim Jong-un attended an Unhasu concert just days before the ensemble departed - the March 8 Women's Day concert, at which they played, not the Paris repertoire, but a very traditionally North Korean program. Among the visible individuals when it came to the Unhasu trip was Kim Ki-nam, the head of regime propaganda, who was there to greet the Unhasu before their trip to Paris.

From the North Korean perspective, the Unhasu Orchestra was deeply entwined with the celebration and earliest postmortem re-formation of Kim Jong-il's legacy. As the vehicle for a cantata, the orchestra expanded greatly and went on a punishing performance schedule in January, not simply in Pyongyang, but also the east coast city of Hamhung and the remote city of Huichon, site of a signature dam meant to remind urban dwellers of Kim Jong-il's commitment to solving problems of electricity 
and living standards in the DPRK. While the orchestra's main repertoire in Paris was that of Western romantic composers Johannes Brahms and Camille Saint-Saëns, a normal consumer of North Korean state media would take away the obvious message of Unhasu's tour to Paris: imbued with the spirit of Kim Jong-il, the orchestra was flying to spread the news of the Kimist renaissance to Europe.

If it represented Kim Jong-il's undying benevolence to the folks back home, the orchestra's appearance in Europe was also intended to send the important message to potential donors to North Korea that the country is receptive to contact with the outside. The musicians did their job here, appearing at the Louvre, where they posed with the Mona Lisa, and spending a day at Versailles. Chinese news agency Xinhua, among the most eager boosters of the notion of North Korea opening up, quoted a French violinist who said, "With this collaboration, opening itself to the world they will soon be at the level of their neighbors."

Inadequate harvests and concerns about international condemnation certainly did not in and of themselves create the Unhasu Orchestra's trip to Paris, but the events are not unconnected. Indeed, the Unhasu's concert was useful in giving Europeans the idea that the DPRK was on the verge of opening up to the outside, and that aid, in spite of all appearances to the contrary, would be used not for military purposes.

Yet even as the halcyon images flowed out of Paris, and visions developed of future performances of Beethoven's Ninth, and Pyongyang violinists wowed audiences with their command of Stradivari, news coming out of Pyongyang was sending precisely the opposite message. One of the lead items on the North Korean news on March 14 were drills by the "Red Guard Worker-Peasant Militia" doing target practice on Lee Myung Bak's name. University students, presumably the core of the new digital-cosmopolitan elite that would emerge to grasp the hand of the world, were volunteering for military service and vowing to become one of "five million human bombs to defend the sacred dignity of the DPRK's leaders." These kind of wildly bellicose statements underscore the duality of North Korea's strange "hammer and hanbok" public relations strategy. As in the case of the missile launch on the day the AP-KCNA photography exhibit ended, the North Koreans appear to have completely squandered the good feelings engendered by the external activities.

\section{Axioms of North Korean Cultural Diplomacy}

Based upon our analysis of the two case studies, the following can be inferred as representing basic components of any exchange. North Korean cultural diplomacy:

1. Kindles hope for reform (at least among the hopeful) and implies that engagement with the DPRK is both likely and possible.

For the DPRK, engaging in cultural diplomacy strengthens the external notion that there exists within the North Korean power-elite a cohort of softliners - rarely identified by name - willing to entertain overtures for nego- 
tiation from outside parties, particularly the United States. When put more realistically, the argument goes that such interactions help to normalize contact with the West among midlevel DPRK officials and elites who presumably will someday drive policy. What this approach completely misses is that highly orthodox men like Kim Ki-nam appear to be in charge of such efforts and that (here and now in the present, not an ideal future) the efforts themselves are participated in as part of regime propaganda, wholly. This is not a case of soft-liners sending out delegations while persuading colleagues at home that cultural embassies are a worthwhile activity for their own sake or that more cultural diplomacy is the vehicle through which the DPRK can be internally transformed.

2. Represents a fraught opportunity for targeted national governments. There is a 100 percent chance of cultural diplomacy being used by North Korea for "propaganda purposes" and an opportunity to showcase and bolster the North's "unique" social and political systems as good. A primary goal here is to increase the prestige of the cult of the leader.

3. Involves North Korean institutions and individuals who are presumably loyal enough to the system as to avoid the risks of defection or public embarrassment. ${ }^{20}$

4. Has peripheral benefits for North Korean participants, which may include the obtaining of foreign exchange and certainly is a more informal means of supplying core classes in Pyongyang with luxury goods from abroad.

5. Plays a key part of what could be cynically characterized as the North's cycle of "provoke, entice, obtain, betray (give nothing)." Cultural diplomacy, as a form of soft power, serves the role of enticing its intended recipient before obtaining and betraying.

6. Has unknown effects in the DPRK. Due to the near complete lack of reliable information coming out of North Korea, it is very difficult to know how, exactly, North Korean citizens themselves view cultural-diplomatic feats or if these activities result in more friendly feelings toward outsiders.

7. Results in varying degrees of ongoing cooperation, more often one-sided outcomes of unrequited cooperation; although the KCNA-AP case may be unique if the AP's presence in Pyongyang, despite limits to freedom of movement, is read as ongoing cooperation on behalf of the DPRK.

In the Unhasu case, it seems that skeptics may, more or less, be correct in identifying that this is a one-way street. Though North Korea may be cooperating to send its orchestra, there is nothing that happened during the event that suggests an ongoing two-way cooperation with France, unless, that is, the event is interpreted more broadly as EU orchestral diplomacy with North Korea, which has continued with the visit of the Munich Chamber Orchestra to Pyongyang. The KCNA-AP case, however, is different from the Unhasu case and all others that have preceded it. There is here a case of specific and ongoing two-way cooperation, even if that cooperation is somewhat lopsided in that it favors North Korean national interests so heavily. 
As to what might be termed a socialization process borne out of the new KCNAAP relationship, Pyongyang Bureau Chief Jean Lee sees that the KCNA reporters working with her and other AP personnel for training purposes, are not only nonresistant to the process but are seemingly be transformed by it. Lee states:

There is no resistance. They are keen to learn how Western journalism works, and they see it as an opportunity to practice their English. I've also seen them adopt Western reporting techniques over the last year. They take what they need and they try and learn from it. It's really important to build these relationships. North Korea is a closed country and they are suspicious of outsiders, so it takes time. There is quite a lot of training involved! ${ }^{21}$

The AP's belief in building trust through cooperation appears thus as part of a larger and positive process of globalization and internalization in the DPRK. Is it so far-fetched to wonder if such cooperation could, if nurtured, serve as a steppingstone in a much broader effort to improve U.S.-DPRK relations? Similarly, the notion that a North Korean orchestra in Paris might both serve Pyongyang's propaganda goals and improve long-term relations with France obviously needs to be entertained. Western liberal democracies are strong enough to handle DPRK propaganda for what it is. While North Korea's state news agency may sometimes bend facts to a grotesque degree, there is no risk of "ideological contamination" in the West as a result of interactions with North Korean groups.

What if marginal change, the likes of which the KCNA-AP represents, is not a harbinger of bigger, more significant change? What if the smoke signals are insignificant? The answer, though disdained by many liberals and optimists alike, is simple: so be it. The point is to not let an uncomfortable history needlessly limit our capabilities to look at every new case anew and be open to signs of actual change and consider its positive consequences.

Our article and the arguments presented within are not intended to support the "hope springs eternal" school of thought. In other words, we are not suggesting that a relative increase in cultural diplomacy is clear evidence that structural reform is afoot inside the DPRK. ${ }^{22}$ Additionally, as we made clear earlier in the article, efforts at engaging the world through using cultural interaction as the medium of exchange is not a unique trait of the new Kim Jong-un regime. We are not linking the sending of the Unhasu Orchestra or the new relationship between the KCNA and the AP as signs that broader reform in the economic or political realm is just steps behind.

What we are arguing for, though, is for a reframing of the problem of the DPRK's institutional cultural interactions with the outside world, and for a study of those interactions that has much greater empirical and theoretical detail; there is an inbetween space nestled somewhere between Sunshine Policy enthusiasts and distrustful polemics. After all, as many North Korea watchers are still wont to argue, efforts at a "charm offensive" out of Pyongyang is nothing but a show and cultural engagement is not indicative of anything larger. Their conclusion is thus: cultural diplomacy is the DPRK's effort to completely dupe the outside and we should thus ignore 
the signals sent and any relationships established. Except those advocating complete containment and collapse, there is a consensus that engagement with North Korea is needed, when appropriate, at all levels possible. What we have shown throughout this article is that this is indeed happening now at the cultural level - or, in diplomatic-talk, at the level of track-two diplomacy. In analyzing engagement at the cultural level we must, as Joseph Nye and other soft-power advocates suggest, operate under the assumption that North Korea - like all countries - is not immune from the laws of soft power, going both ways. North Korea has the capacity to both attract and be attracted.

\section{Notes}

1. Other examples of hints of internationalization include more domestic media attention to foreign language study, concerts for Kim Jong-un and his wife featuring songs by Richard Clydermann, the opening of a "Viennese" cafe in Pyongyang, and the ability of foreigners in Pyongyang (and reportedly Rason) to make cell phone calls outside of the country, among others.

2. Joseph Nye introduced the concept of "soft power." Joseph Nye, Bound to Lead: The Changing Nature of American Power (New York: Basic Books, 1990).

3. Joseph S. Nye, Jr., Soft Power: The Means to Success in World Politics (New York: Public Affairs, 2004), pp. 5-15.

4. Charles K. Armstrong, "The Cultural Cold War in Korea, 1945-1950," The Journal of Asian Studies 62, no. 1 (2003), pp. 71-99. http://dx.doi.org/10.2307/3096136

5. Ibid., p. 83.

6. Adam Cathcart, "The Sea of Blood Opera Show: A History of North Korea's Musical Diplomacy," The Atlantic, March 19, 2012.

7. B.R. Myers, Han Sorya and North Korean Literature: The Failure of Socialist Realism in the DPRK (Ithaca: Cornell University Press, 1994), pp. 73-85.

8. Ding Ying, "Diplomacy Hits a High Note: The New York Philharmonic's Concert in North Korea Turns a New Page in the History of North Korean-U.S. Relations,” Beijing Review, March 13, 2008, p. 12.

9. For analysis of the New York Philharmonic trip, including repertoire choices and impacts, see Adam Cathcart, "North Korean Hip Hop? Reflections on Musical Diplomacy and the DPRK," Acta Koreana 12, no. 2 (December 2008), pp. 1-19.

10. "AP/KCNA Photo Exhibit Opens in New York," North Korea Tech, March 17, 2012, http://www.northkoreatech.org/2012/03/17/apkcna-photo-exhibit-opens-in-new-york/.

11. The AP's Video Network had been operating in Pyongyang, staffed by North Koreans and managed by AP personnel from Hong Kong since 2006. Michael Calderone, "Associated Press North Korea Bureau Opens as First All-Format News Office in Pyongyang," Huffington Post, January 16, 2012, http://www.huffingtonpost.com/2012/01/16/associated-press-north-korea-bureau-pyong yang_n_1208159.html.

12. "The Associated Press Announces Agreements to Expand Access in North Korea," The Associated Press, June 29, 2011, http://www.ap.org/Content/Press-Release/2011/The-AssociatedPress-announces-agreements-to-expand-access-in-North-Korea.

13. It should be noted that efforts by the North Korean government to expand its international contacts through intermedia cooperation had started prior to its agreement with the AP. Agreements had been signed with China, and KCNA staff began, in very limited numbers, to expand into international conference activity in relatively friendly places like Moscow. A bureau was opened in Beijing (which may have since closed) and Internet presence vastly improved at Rodong Sinmun.

14. "A Window on North Korea: Photographs from the DPRK," The Associated Press, March 16, 2012, http://www.ap.org/Content/Press-Release/2012/Window-on-North-Korea-PhotographsFrom-the-DPRK.

15. Ibid. 
16. Maria Sanminiatelli, "Photo Show Offers Rare Glimpse of life in N. Korea," The Washington Times, March 15, 2012, http://www.washingtontimes.com/news/2012/mar/15/photo-showoffers-rare-glimpse-of-life-in-n-korea/.

17. As of this writing, the quote provided by the KCNA cannot be verified by other news sources, indicating that the quote may in fact be completely fabricated as a way to convey the usual message that the DPRK seeks political reconciliation and eventual unification with the South. See below, "KCNA-AP Joint Photo Exhibition Opens in the U.S."

18. "KCNA-AP Joint Photo Exhibition Opens in the U.S.," Korean Central News Agency, March 15, 2012, http://www.kcna.co.jp/item/2012/201203/news16/20120316-22ee.html.

19. To view some of the photos on display, see: http://lens.blogs.nytimes.com/2012/03/16/ north-korea-in-contrast/; and http://www.rodong.rep.kp/InterKo/index.php?strPageID=SF01_02_ 02\&newsID=2012-04-11-0048.

20. However, this is a problem that really should be studied more systematically; we lack biographies of the most public faces of North Korean diplomacy (for instance, vice foreign ministers; this tendency toward blank pages is exacerbated by the DPRK's own tendency to give diplomats who go abroad alternate identities and not allow for consistent interpersonal contact with foreign interlocutors).

21. Hazel Sheffield, “The AP's North KoreanBureau," Columbia Journalism Review, August 2, 2012, http://www.cjr.org/behind_the_news/the_aps_north_korea_bureau.php?page=all.

22. Bruce Klingner, "Waiting for North Korean Reform ... and Waiting," DailyNK, August 21, 2012, http://www.dailynk.com/english/read.php?cataId=nk03600\&num=9698.

\section{Biographical Statements}

Adam Cathcart is lecturer at Leeds University in the UK and the editor-in-chief of SinoNK.com. His research and publication program falls into three broad categories: China-North Korea relations, Sino-Japanese relations, and East-West cultural relations. He has been interviewed by the BBC, NPR, and Huffington Post Live, and quoted in the Wall Street Journal and Reuters. His writings have been featured in The Atlantic, Foreign Policy, The Diplomat, and the Daily NK. He is the coauthor of a book manuscript concerning North Korean-Chinese relations and borderlands from 1945 to 1950.

Steven Denney is a Ph.D. student in the Department of Political Science at the University of Toronto and the managing editor of SinoNK.com. His research and writing efforts revolve around three general categories: North-South relations, South Korean domestic politics, and the political economy of Northeast Asia. He is currently doing research on political socialization and the democratic process in South Korea. His writings have been featured in CSIS's PacNet, Asia Times, e-IR.com, and The Korean Quarterly. 